\title{
Tendências e práticas de aproximação entre os textos literários e o ensino de ciências
}

\author{
Trends and practices of the approach between literary texts and \\ science teaching
}

\author{
Sabrine Lino Pinto ${ }^{1}$ \\ Sônia Cristina Vermelho²
}

\section{Resumo}

Considerando a importância do hábito da leitura como prática social que possibilite a articulação da literatura aos conteúdos científicos para auxiliar os professores de ciências no processo de ensino-aprendizagem e motivar os alunos a aprender, foi realizada uma pesquisa bibliográfica com o objetivo de investigar o que tem sido produzido acerca da relação ensino de ciências e literatura trabalhada no ensino fundamental dentro do espaço escolar. Para tanto, realizou-se um estudo bibliométrico exploratório e descritivo em 05 (cinco) bases de dados, cuja busca foi feita pelos termos literatura, ensino de ciências, alfabetização e educação científica, que levaram a uma seleção final de 20 trabalhos analisados na integra. Os resultados mostraram que, embora a inclusão de textos literários em sala de aula promovem o diálogo produtivo para o processo de ensino-aprendizagem de ciências, é uma temática que merece ser mais explorada, tanto nas pesquisas de revisão da literatura, como também de experiências práticas, o que permite concluir que, no que tange à relação biblioteca e ensino de ciências, se trata de um assunto muito pouco explorado, quase inédito, pois, não foi recuperado na busca nenhum artigo que tratasse dessa relação.

Palavras-chave: Ensino de Ciências. Literatura. Ensino fundamental.

\section{Abstract}

Considering the importance of the habit of reading as a social practice that allows the articulation of literature to scientific contents to assist science teachers in the teaching-learning process and to motivate students to learn,

\footnotetext{
${ }^{1}$ Doutoranda em Educação em Ciências e Saúde do Programa de Pós-graduação do NUTESUFRJ. Atualmente é bibliotecária-documentalista do Instituto Federal de Educação, Ciência e Tecnologia do Espírito Santo. E-mail: brinevix@gmail.com

2 Pós-Doutora do INESC/Universidade do Porto, Portugal no Laboratório de Sistemas de Informação e Computação Gráfica (2014). Atualmente é professora adjunta da Universidade Federal do Rio de Janeiro, no Programa de Pós-Graduação em Educação em Ciências e Saúde vinculado ao Núcleo de Tecnologia Educacional para Saúde - NUTES, no Laboratório de Linguagens e Mediações. E-mail: cristina.vermelho@gmail.com
} 
a bibliographical research was carried out with the objective of investigating what has been produced about the relation between science teaching and literature worked in elementary education within the school space. In order to, an exploratory and descriptive bibliometric study was carried out in 05 (five) databases, whose search was done by the terms literature, science teaching, literacy and scientific education, which led to a final selection of 20 papers analyzed in their entirety. The results showed that, although the inclusion of literary texts in the classroom promote productive dialogue for the process of teaching-learning of science, it is a topic that deserves to be more explored, in the researches of revision of the Literature, as well as practical experiences, which allows us to conclude that, as far as the relation between library and science education is concerned, it is a very little explored subject, almost unheard of, since no article dealing with this relation was retrieved.

Keywords: Science teaching. Literature. Elementary School.

\section{INTRODUÇÃO}

Um dos objetivos centrais do ensino de ciências é promover o interesse dos alunos acerca da importância dos conteúdos científicos na sua formação como cidadãos críticos, para que possam compreender os problemas gerados pelo modelo produtivo e social marcadamente consumista e excludente. Nesse sentido, a introdução da leitura de textos literários no ensino de ciências pode auxiliar os professores no processo de ensino-aprendizagem de uma forma prazerosa e lúdica, e também condizente com os conteúdos curriculares.

Independente da área disciplinar, a leitura caracteriza-se como um fator potencial da democracia e da cidadania para que esse sujeito compreenda o mundo que o cerca e também compreenda, absorva e reflita sobre o conhecimento apreendido na escola. Um dos maiores desafios hoje é atrair o aluno para o que é ensinado em sala de aula, sem necessitar de impor sacrificios para ele e transformar a educação em algo agradável e proveitoso. Também é bastante desafiador 
estimular os professores a buscarem alternativas diferenciadas para o alcance do diálogo produtivo para motivar seus alunos. Uma das alternativas que consideramos significativa é a introdução da literatura como forma de suscitar o interesse no Ensino de Ciências.

Nessa perspectiva, este artigo traz os resultados de uma pesquisa bibliográfica em que identificamos pesquisas que tratavam da relação da literatura e o ensino de ciências no nivel da educação fundamental. A proposta desta pesquisa está aliada ao reconhecimento da importância do hábito da leitura como prática social que influencia a formação, em especial, com a possibilidade de articulação da literatura aos conteúdos científicos, reconhecendo que essa articulação pode se apresentar como uma prática que auxilie os professores de ciências sobre a natureza no processo de ensino-aprendizagem, para motivar os alunos para aprender, estimulando a crítica e a contextualização.

\section{A LITERATURA NO ENSINO DE CIÊNCIAS}

O ensino das Ciências, segundo Santos e Mortimer (2002), Santos (2007b) e Santos (2008), tem o intuito de promover um ensino democrático, crítico e contextualizado visando à formação de cidadãos autônomos, propiciando a reflexão acerca das concepções de ciência e dos modos de desenvolvimento do conhecimento científico, buscando tornar os alunos mais aptos a participarem nas decisões que envolvem a inovação científica e tecnológica. Apesar da intensidade e rapidez com que as ciências, de modo geral, são imbricadas na sociedade contemporânea, aos olhos dos individuos, esse processo é quase imperceptivel, já que faz parte do cotidiano da maioria da população que vivencia os avanços científicos de forma quase que habitual e rotineira, seja nos avanços na medicina, na produção de alimentos e 
na melhoria (ou não) da qualidade de vida. A população não participa dos processos de decisão em relação a direção e as prioridades para o desenvolvimento da ciência e da tecnologia. Esse contexto, segundo os documentos oficiais, colocaria a exigência para a escola de promover "[...] o exercício da compreensão, valorização da ciência e da tecnologia desde a infância e ao longo de toda a vida, em busca da ampliação do domínio do conhecimento científico: uma das condições para o exercício da cidadania” (BRASIL, 2013, p. 26), conforme defendido pelas Diretrizes Curriculares Nacionais da Educação Básica (DCNEB).

Ainda que pese a necessidade de se reconhecer a importância da ciência e da tecnologia na sociedade, consideramos fundamental pensar criticamente acerca do modo como se dá o seu desenvolvimento, pois compreendemos que dominar a tecnologia é condição para uma atuação com autonomia, o que é requisito para uma ação cidadã. Marcuse (1969), em sua crítica à sociedade moderna e industrial, nos alerta para o fato de que a sociedade ocidental nos marcos do capitalismo promove o:

[...] desenvolvimento das forças produtivas em escala ampliada, [aumenta] a extensão da conquista da natureza, [alcança uma] crescente satisfação das necessidades de número cada vez maior de pessoas, [também atua na] criação de necessidades e faculdades novas. Mas essas possibilidades estão sendo gradativamente realizadas por meios e instituições que cancelam seu potencial libertador, e esse processo afeta não apenas os meios, mas também seus fins (MARCUSE, 1969, p. 233).

Com isso, a ciência avança, a tecnologia adentra o cotidiano e passa a ser utilizada cada vez mais nas atividades cotidianas, enquanto as condições de vida e de liberdade $^{3}$ real diminuem. Temos

3 Usamos o conceito de liberdade segundo a Teoria Crítica Social, segundo a qual,
resumidamente, entende que não se trata de possibilidade de escolha de compra. Liberdade
é de escolha de vida e não de consumo. Para maior aprofundamento da discussão,
indicamos os textos: ADORNO, Theodor W.; HORKHEIMER, Max. Dialética do Interfaces da Educ., Paranaíba, v.8, n.24, p. 119-146, 2017. 
tecnologia avançada de comunicação, mas ainda temos fome e miséria em todos os cantos do planeta. As contradições da sociedade são visíveis a olho nu, mas suas causas não são compreensiveis sem um esforço de análise e reflexão. Consideramos que um dos aspectos que contribuem para a compreensão da realidade de maneira mais profunda é o hábito da leitura e da reflexão. O que coloca um grande desafio para a educação na atualidade, pois, por um lado, avançamos em relação às tecnologias da comunicação e informação, por outro, o processo formativo nas escolas públicas tem tendencialmente diminuído na construção de hábitos de um determinado tipo de leitura. O que observamos é que é estimulado uma leitura rápida, de textos curtos, mas muito pouco de textos que estimulem a imaginação, a abstração e a reflexão.

Acreditamos que o estímulo para a leitura da literatura na educação básica pode ser uma forma que contribua para uma prática social que estimule a reflexão e também a aprendizagem dos conteúdos científicos, muitas vezes, cheios de regras e dificeis de entender. A leitura não é solução, mas o hábito de leitura faz parte do processo de formação; importante salientar que compreendemos que a leitura está além do ler e escrever, mas trata-se de fundamento essencial ao pensamento humano. De acordo com Palcha e Oliveira (2014, p. 103), o funcionamento social da leitura e da literatura pode ser considerado

[...] um processo simbólico plural e reflexivo de compreensão da realidade. Na relação com o saber, ambos os processos operam sob os processos de significação, e, portanto, a escola como uma instituição produtora do conhecimento precisa

Esclarecimento: fragmentos filosóficos. 2. ed. Tradução: Guido Antonio de Almeida. Rio de Janeiro: Jorge Zahar, 1985; ADORNO, Theodor W. Teoria da pseudocultura. In: HORKHEIMER, M. e ADORNO, T. W. Sociológica. Madrid: Taurus, 1971. 
promover reflexões acerca da relação de sentidos entre o ensino e a linguagem.

Também consideramos que a proposta de introduzir a literatura no ensino de ciências está relacionada com a importância de aproximar o lúdico da vida escolar, pois, de acordo com Neves (2013, p. 17), a ludicidade "facilita a aprendizagem, o desenvolvimento social, pessoal e cultural e colabora com a boa saúde mental e física do indivíduo para vida toda" e se relaciona com o processo de formação em aspectos como a criação, a imaginação e a produção. Nesse sentido, "no processo de aprendizagem a área cognitiva está inseparavelmente ligada à afetiva e à emocional", assim como é nas nossas atividades diárias, nas quais, o prazer, a fantasia e o desejo estão imbricados, como também defende as DCNEB (BRASIL, 2013, p. 116).

Desse modo, a literatura pode se transformar num mundo de descoberta, que instiga a curiosidade e pode servir à Educação para motivar o gosto pela leitura. Ela projeta o leitor em outras direções e possibilita o compartilhamento de descobertas e experiências, inclusive as científicas e tecnológicas, que ocupam "um lugar na literatura e nas outras artes para louvar suas conquistas, seja para alertar sobre seus perigos, seja para pura e simples admiração das possibilidades que elas trazem" (PIASSI, 2007, p. 262).

Tendo em vista esse contexto, realizamos uma pesquisa bibliográfica para identificar qual a produção sobre a relação da literatura na educação fundamental, em especial para o ensino de ciências. 


\section{ESCOPO DA PESQUISA}

Para a identificação dos textos, foi realizada uma investigação no mês de setembro de 2016 para identificar artigos e teses e dissertações sobre o tema Literatura e ensino de ciências. Realizamos o levantamento nas bases de dados da Revista Brasileira de Educação (RBE), da Revista Brasileira de Pesquisa em Educação em Ciências (RBPEC), do Scientific Electronic Library Online (SciELO), do Portal de Periódicos da Coordenação de Aperfeiçoamento de Pessoal de Nivel Superior (Capes) e da Biblioteca Digital Brasileira de Teses e Dissertações (BDTD).

Os critérios de inclusão/exclusão foram assim definidos: a busca em qualquer idioma, sem delimitações de data ou período de publicação e a busca pelas palavras-chave "literatura" e "ensino de ciências" com o uso dos operadores booleanos "exato" e "and", repetindo-se esse mesmo critério para as palavras-chave "literatura", "alfabetização" e "educação científica". O uso dos operadores booleanos foi necessário, pois, sem os mesmos, as buscas resultavam numa quantidade elevada de títulos, como no caso do Portal de Periódicos da Capes. Dessa forma, foi possivel obter uma busca mais refinada dos trabalhos em que os campos do ensino de ciências estivessem articulados com a literatura, pois, na ausência dos operadores, apareciam pesquisas que remetiam à área de educação e ensino em geral ou a área de letras, da língua portuguesa, da linguística ou da literatura, sem qualquer ligação com a área de ciências. Similarmente, por esse mesmo motivo, nas bases de dados SciELO e BDTD foi necessário, durante as buscas, o uso das palavras-chaves "ensino de", "educação em", "ensino em" e "educação de" delimitadas entre aspas, para também, tornar os resultados mais direcionados. 
Ademais, durante essa investigação, verificamos que os resultados das buscas quando se utilizavam os termos "ensino de" e "educação em" diferenciavam-se dos termos "ensino em" e "educação de", e, por isso, também foi realizado o levantamento com esses termos em conjunto com a palavra-chave "literatura". No intuito de uma revisão mais aprofundada e específica, também foi realizado o levantamento com os termos alfabetização/educação científica, "ensino de", "educação em", "ensino em" e "educação de" juntamente com as palavras-chave "biblioteca" e "mídia educação".

Os dados coletados dos trabalhos foram: título, autor (es), ano de publicação, instituição de vinculação do (s) autor (es), palavras-chave e o resumo. Esses dados foram organizados numa planilha do Excel e posteriormente foram realizadas as análises quantitativas $\mathrm{e}$ qualitativas por meio de análise do conteúdo a partir de categorias analiticas.

Por meio desse levantamento inicial, foram identificados um total de 1.105 publicações, divididas em 2 livros (0,18\%), 714 artigos (64,61\%), 296 dissertações de mestrado (26,79\%) e 93 teses de doutorado (8,42\%). Em relação à fonte desses materiais, nas Tabelas 1 e 2, apresentamos a sua distribuição segundo as palavras-chave e a fonte de pesquisa.

Tabela - Distribuição dos artigos segundo a palavra-chave de pesquisa.

\begin{tabular}{l|c|c}
\hline \multicolumn{1}{c|}{ Palavra-chave pesquisa } & Freq. & $\%$ \\
\hline Literatura and ensino de ciências & 271 & $24,5 \%$ \\
\hline Literatura and educação científica & 176 & $15,9 \%$ \\
\hline $\begin{array}{l}\text { Literatura and educação em } \\
\text { ciências }\end{array}$ & 149 & $13,5 \%$ \\
\hline $\begin{array}{l}\text { Literatura and educação de } \\
\text { ciências }\end{array}$ & 121 & $11,0 \%$ \\
\hline
\end{tabular}




\begin{tabular}{l|c|c} 
Literatura and ensino em ciências & 81 & $7,3 \%$ \\
\hline Biblioteca and ensino de ciências & 56 & $5,1 \%$ \\
\hline $\begin{array}{l}\text { Mídia educação and ensino de } \\
\text { ciências }\end{array}$ & 45 & $4,1 \%$ \\
\hline $\begin{array}{l}\text { Literatura and alfabetização } \\
\text { científica }\end{array}$ & 34 & $3,1 \%$ \\
\hline $\begin{array}{l}\text { Mídia educação and educação } \\
\text { científica }\end{array}$ & 33 & $3,0 \%$ \\
\hline $\begin{array}{l}\text { Mídia educação and educação em } \\
\text { ciências }\end{array}$ & 28 & $2,5 \%$ \\
\hline $\begin{array}{l}\text { Biblioteca and educação científica } \\
\text { Biblioteca and educação em } \\
\text { ciências }\end{array}$ & 27 & $2,4 \%$ \\
\hline $\begin{array}{l}\text { Mídia educação and educação de } \\
\text { ciências }\end{array}$ & 22 & $2,0 \%$ \\
\hline $\begin{array}{l}\text { Biblioteca and ensino em ciências } \\
\text { Biblioteca and educação de } \\
\text { ciências }\end{array}$ & 14 & $1,7 \%$ \\
\hline $\begin{array}{l}\text { Mídia educação and ensino em } \\
\text { ciências }\end{array}$ & 9 & $0,8 \%$ \\
\hline $\begin{array}{l}\text { Mídia educação and alfabetização } \\
\text { científica }\end{array}$ & 6 & $0,5 \%$ \\
\hline $\begin{array}{l}\text { Biblioteca and alfabetização } \\
\text { científica }\end{array}$ & 5 & $0,5 \%$ \\
\hline \begin{tabular}{l} 
Total \\
\hline
\end{tabular} & 1105 & $100,0 \%$ \\
\hline
\end{tabular}

Fonte: Elaborada pelas autoras, 2017.

Tabela 2 - Distribuição dos artigos segundo a fonte de pesquisa.

\begin{tabular}{|c|c|c|}
\hline Fonte & Freq. & $\%$ \\
\hline IBICT & 385 & 35 \\
\hline Scielo & 605 & 55 \\
\hline CAPES & 54 & 4,9 \\
\hline Revista RBPPEC & 60 & 5 \\
\hline $\begin{array}{l}\text { Revista Brasileira de } \\
\text { Educação }\end{array}$ & 1 & 0,1 \\
\hline Total & 1105 & 100 \\
\hline
\end{tabular}

Desse número total inicial de 1.105 títulos, eliminamos repetições e selecionamos pelo título os trabalhos que voltados 
diretamente para a relação da literatura ou da prática de leitura no ensino de ciências, resultando em 81 trabalhos. Desse conjunto de trabalhos, realizamos a última seleção, lançando mão dos resumos, tendo como critério os trabalhos que estavam diretamente ligados à relação entre literatura e ensino ou educação em ciências na educação básica. Mesmo que em alguns trabalhos o termo literatura não estivesse literalmente descrito no título, a seleção destes foi feita por conterem palavras ou termos que remetiam a gêneros literários, como ficção científica e contos, por exemplo, evidenciados mediante a leitura dos seus resumos.

Dessa última seleção, foram selecionados 20 trabalhos que estavam ligados diretamente ao tema literatura e ensino de ciências na educação básica que foram objeto de estudo desta revisão bibliográfica, sendo que 7 deles são dissertações, 3 são teses e 10 são artigos. No que diz respeito às teses e dissertações, a USP foi a instituição que mais produziu trabalhos com esse tema, num total de 4 trabalhos, sendo que as outras instituições - UFPR, UNESP, UFRN, UFSC, UTFPR e FIOCRUZ - produziram 1 trabalho cada uma. Quanto aos artigos, os resultados demonstraram que o periódico que mais publicou foi a revista Ensaio Pesquisa em Educação em Ciências com 6 artigos publicados, seguido da revista Ciência \& Educação com 3 artigos e a revista Educação e Pesquisa com 1 título.

Em termos de periodo em que esse tema aparece nas pesquisas, dentro do corpus analisado, mostrou ser um assunto novo, pois, todos os trabalhos foram publicados todos após 2005. A Tabela 3 mostra o quantitativo destes trabalhos por ano. 
Tabela 3 - Distribuição dos artigos, segundo o ano de publicação

\begin{tabular}{c|c}
\hline Ano & Qtde \\
\hline 2007 & 2 \\
\hline 2008 & 3 \\
\hline 2009 & 2 \\
\hline 2010 & 0 \\
\hline 2011 & 1 \\
\hline 2012 & 2 \\
\hline 2013 & 3 \\
\hline 2014 & 3 \\
\hline 2015 & 3 \\
\hline 2016 & 1 \\
\hline Total & 20 \\
\hline
\end{tabular}

Fonte: Elaborada pelas autoras, 2017.

Por último, realizamos uma seleção de trabalhos que tinham como foco a formação discente no ensino fundamental. Do total de 20, selecionamos 13 trabalhos, sendo que 7 foram descartados porque 3 eram voltados para o ensino médio, 1 para a educação infantil, 2 para a formação docente e 1 para a formação continuada de professores. Esses 13 trabalhos, relacionados no Quadro 1, foram lidos na íntegra.

Quadro 1 - Trabalhos selecionados para análise de conteúdo.

\begin{tabular}{|c|l|l|l|l|}
\hline N. & \multicolumn{1}{|c|}{ Título } & \multicolumn{1}{|c|}{$\begin{array}{c}\text { Tipo de } \\
\text { publicação }\end{array}$} & $\begin{array}{c}\text { IES/ } \\
\text { Periódico }\end{array}$ & Ano \\
\hline 1 & $\begin{array}{l}\text { A ficção científica e o estranhamento } \\
\text { cognitivo no ensino de ciências: estudos } \\
\text { criticos e propostas de sala de aula }\end{array}$ & Artigo & $\begin{array}{l}\text { Ciência \& } \\
\text { Educação }\end{array}$ & 2013 \\
\hline 2 & $\begin{array}{l}\text { A literatura de Monteiro Lobato na } \\
\text { discussão de questões acerca da natureza } \\
\text { da ciência no ensino fundamental }\end{array}$ & Artigo & $\begin{array}{l}\text { Ciência \& } \\
\text { Educação }\end{array}$ & 2015 \\
\hline 3 & $\begin{array}{l}\text { Aproximações entre literatura e ciência: um } \\
\text { estudo sobre os motivos para utilizar textos } \\
\text { literários no ensino de ciências }\end{array}$ & Dissertação & UFP & 2014 \\
\hline 4 & $\begin{array}{l}\text { Biologia e cultura: significações partilhadas } \\
\text { na literatura de monteiro lobato }\end{array}$ & Artigo & $\begin{array}{l}\text { Ensaio } \\
\text { Pesquisa em } \\
\text { Educação em } \\
\text { Ciências }\end{array}$ & 2007 \\
\hline 5 & $\begin{array}{l}\text { Contatos: a ficção científica no ensino de } \\
\text { ciências em um contexto sociocultural }\end{array}$ & Tese & USP & 2007 \\
\hline 6 & $\begin{array}{l}\text { Detetive ou cientista? A literatura policial } \\
\text { infanto-juvenil como recurso didático na } \\
\text { educação em ciências }\end{array}$ & Dissertação & USP & 2013 \\
\hline 7 & Ficção científica e ensino de ciências: para & Artigo & Educação e & 2009 \\
\hline
\end{tabular}




\begin{tabular}{|c|c|c|c|c|}
\hline & $\begin{array}{l}\text { além do método de 'encontrar erros em } \\
\text { filmes' }\end{array}$ & & Pesquisa & \\
\hline 8 & $\begin{array}{l}\text { Leitura coletiva de um texto de literatura } \\
\text { infantil no ensino fundamental: algumas } \\
\text { mediações pensando o ensino das ciências }\end{array}$ & Artigo & $\begin{array}{l}\text { Ensaio } \\
\text { Pesquisa em } \\
\text { Educação em } \\
\text { Ciências }\end{array}$ & 2008 \\
\hline 9 & $\begin{array}{l}\text { Literatura de Monteiro Lobato no ensino de } \\
\text { ciências }\end{array}$ & Dissertação & UFRN & 2012 \\
\hline 10 & Literatura infantil no ensino de ciências & Dissertação & UFSC & 2008 \\
\hline 11 & $\begin{array}{l}\text { Literatura não-canônica de divulgação } \\
\text { científica em aulas de ciências }\end{array}$ & Artigo & $\begin{array}{l}\text { Ensaio } \\
\text { Pesquisa em } \\
\text { Educação em } \\
\text { Ciências }\end{array}$ & 2009 \\
\hline 12 & $\begin{array}{l}\text { Monteiro Lobato em aulas de ciências: } \\
\text { aproximando ciência e literatura na } \\
\text { educação científica }\end{array}$ & Artigo & $\begin{array}{l}\text { Ciência \& } \\
\text { Educação }\end{array}$ & 2015 \\
\hline 13 & $\begin{array}{l}\text { O sapo virou príncipe: construção do } \\
\text { conhecimento sobre a classe amphibia a } \\
\text { partir de contos infantis e sua importância } \\
\text { no ensino de ciências }\end{array}$ & Dissertação & FIOCRUZ & 2014 \\
\hline
\end{tabular}

Fonte: Elaborado pelas autoras, 2017.

Da leitura integral dos trabalhos, procuramos agrupá-los em dois conjuntos: no primeiro, aqueles que se tratavam de pesquisas empíricas, com alguma intervenção em sala de aula, no qual o pesquisador fez uso da observação e/ou alguma atividade para coleta de dados para o alcance de resultados para sua pesquisa. No segundo conjunto, selecionamos os trabalhos que eram pesquisas teóricas, nas quais os pesquisadores somente se utilizaram de revisões ou abordagens textuais para alcançarem seus resultados.

O primeiro grupo, dos trabalhos empíricos, foi formado por 5 trabalhos: Detetive ou cientista? A literatura policial infanto-juvenil como recurso didático na educação em ciências (SANTOS, 2013); Leitura coletiva de um texto de literatura infantil no ensino fundamental: algumas mediações pensando o ensino das ciências (GIRALDELLI; ALMEIDA, 2008); Literatura de Monteiro Lobato no ensino de ciências (GROTO, 2012); Monteiro Lobato em aulas de ciências: aproximando ciência e literatura na educação científica 
(GROTO; MARTINS, 2015a) e O sapo virou príncipe: construção do conhecimento sobre a classe amphibia a partir de contos infantis e sua importância no ensino de ciências (CABRAL, 2014). Neste grupo, os trabalhos possuem a característica de tratarem de uma prática pedagógica relacionada com a leitura ou da relação dos textos literários no ensino de ciências aplicadas em sala de aula.

Santos (2013) apresenta uma proposta didática aplicada no ensino de ciências em uma escola da cidade de São Paulo com a articulação da literatura do romance policial juvenil intitulado "O caso da borboleta Atíria", da Série Vaga Lume da editora Ática de autoria de Lúcia Machado de Almeida. De acordo com a autora, os livros que compõe essa Série se caracterizam por possuir conteúdos que permeiam várias áreas do conhecimento e fazem parte do acervo de muitas bibliotecas escolares e do repertório de leitura de muitos alunos desde a década de 1970 .

A pesquisa consistiu em analisar a obra mediante o uso da semiótica de Greimas (1976) que estabelece relações sintáxicas do texto para auxiliar uma interpretação mais profunda. Também, a autora realizou a análise do discurso com base em Maingueneau (2006), que possibilitou avaliar as principais características e condições de êxito para os gêneros do discurso e evidenciou aspectos estruturais e do contexto sociocultural da obra que devem ser considerados no processo de ensino-aprendizagem (SANTOS, 2013). A experiência analisada pela autora a levou a concluir que a obra promoveu nos alunos a busca do conhecimento por meio da investigação, o que possibilitou o uso do livro para a elaboração de propostas didáticas, como abordagem da investigação científica no 
Ensino Fundamental II, não só no ensino de ciências, mas de forma interdisciplinar em diversos contextos escolares.

O artigo de Giraldelli e Almeida (2008) analisou a mediação de um texto de literatura infanto-juvenil no ensino de ciências naturais para alunos de uma classe da quarta série do ensino fundamental de uma escola pública na cidade de Campinas - SP. As pesquisadoras observaram e registraram as falas das crianças durante a atividade, que consistiu na leitura coletiva de um texto narrativo. A finalidade da atividade era incentivar a curiosidade desses alunos e contribuir de forma prazerosa para a compreensão dos conhecimentos científicos. Depois da leitura, foi sugerido aos alunos que escrevessem um texto com suas apreensões sobre a aula. A análise dessas falas e dos textos escritos por elas revelaram algumas mediações do texto, entre criançacriança e entre criança-professora pesquisadora e levaram à conclusão de que a atividade foi prazerosa e pôde instigar a curiosidade para a compreensão de conhecimentos sistemáticos abstratos relativos ao ensino de ciências.

O artigo de Groto e Martins (2015a) e de Groto (2012) tem como fonte a mesma pesquisa, por isso, descrevemos juntos. O estudo tinha por objetivo propor uma aproximação entre Ciência e Literatura no Ensino de Ciências, com o uso de duas obras de Monteiro Lobato: A Reforma da Natureza e os Serões de Dona Benta. As autoras partiram do entendimento de que a educação é uma tarefa humanizante e que a literatura possui uma função humanizadora. A pesquisa foi realizada numa abordagem interdisciplinar com a adoção da metodologia da pesquisa-ação com uma turma do $8^{\circ}$ ano e uma turma do $9^{\circ}$ ano do ensino fundamental de uma Escola Estadual localizada no município de Tibau do Sul/RN. 
A escolha do livro A Reforma da Natureza foi motivada pelo fato de que poderia abordar temas relativos ao meio ambiente, enquanto que o livro Serões de Dona Benta poderia oportunizar a problematização de conceitos como massa, peso, matéria e outras questões relativas à Natureza da Ciência. O estudo envolveu a realização das leituras das obras durante as aulas de Língua Portuguesa e a discussão dos conteúdos científicos durante as aulas de Ciências. Os resultados analisados revelaram que a leitura das obras e a discussão advinda delas promoveram a interação e a dialogicidade dos alunos na sala de aula, ficando também comprovado que ambas possuem um potencial para a contextualização e a problematização dos conteúdos científicos presentes nelas. Entretanto, Groto (2012) alerta que tanto essas quanto outras obras literárias trazem consigo alguns erros conceituais, havendo, dessa forma, a necessidade do professor de ciências estar atento a este fato para que aprendizagens equivocadas sejam evitadas.

O trabalho de Cabral (2014) investigou algumas articulações entre Literatura Infantil, Animais da Ordem Anura e Ensino de Ciências, com base na Literatura de Ficção. O objetivo foi fazer uma análise da relação entre a percepção obtida pelos contos infantis na infância e a construção epistemológica que foi desenvolvida no ensino fundamental na disciplina de Ciências.

$\mathrm{Na}$ primeira etapa da pesquisa foi feito um levantamento dos contos infantis que poderiam contribuir para a formação de opinião das crianças acerca dos sapos, rãs e pererecas. A segunda etapa consistiu na aplicação de um questionário para alunos do terceiro e sétimos anos do ensino fundamental do colégio de aplicação da UFRJ com perguntas abertas e fechadas sobre fábulas infantis de 
personagens animais da Ordem Anura e dos conteúdos sobre estes animais que foram trabalhados na disciplina de Ciências. Também foi realizada, como parte dessa etapa, na mesma instituição, uma atividade com os alunos do primeiro ano do ensino fundamental que tinha por objetivo a produção de um desenho, por meio do qual iria ser verificada, nas representações dos alunos sobre os anfíbios anuros, a existência de elementos dos contos infantis (CABRAL, 2014).

Ao realizar a análise, a autora se deparou com duas referências importantes que foram incorporadas como eixos de análise: o ensino informal e a sua influência cultural e o Ensino de Ciências com enfoque na relação teoria $\mathrm{x}$ prática. A análise dos dados ocorreu mediante a criação de três categorias selecionadas no conteúdo pelos critérios da repetição e da relevância, quais sejam: imaginário infantil, aspectos morfológicos (com a inclusão de gênero) e ecológicos, mediante a utilização da técnica de análise do conteúdo temático. A conclusão do estudo evidenciou que a literatura infantil pode ser usada pelos professores de Ciências como suporte para o amadurecimento cognitivo e pessoal dos estudantes, possibilitando a desconstrução da visão do senso comum produzida durante a infância e a construção do conhecimento científico crítico e reflexivo.

No segundo grupo, formado pelos trabalhos teóricos, são expostas algumas reflexões acerca do diálogo produtivo da literatura com alunos do Ensino Fundamental visando facilitar o processo de ensino-aprendizagem dos conteúdos científicos. Alguns trabalhos são caracterizados por trazerem uma análise de obras literárias, enquanto outros relatam o desenvolvimento de instrumentos teóricos de análise, porém, todos com o viés de serem propostas para a aproximação da literatura no ensino de ciências. Essa seção foi formada por 8 
trabalhos: Contatos: a ficção científica no ensino de ciências em um contexto sociocultural (PIASSI, 2007). A ficção científica e o estranhamento cognitivo no ensino de ciências: estudos críticos e propostas de sala de aula (PIASSI, 2013); A literatura de Monteiro Lobato na discussão de questões acerca da natureza da ciência no ensino fundamental (GROTO; MARTINS, 2015b); Aproximações entre literatura e ciência: um estudo sobre os motivos para utilizar textos literários no ensino de ciências (SILOCHI, 2008); Biologia e cultura: significações partilhadas na literatura de Monteiro Lobato (CARVALHO, 2007); Ficção científica e ensino de ciências: para além do método de 'encontrar erros em filmes' (PIASSI; PIETROCOLA, 2009); Literatura infantil no ensino de ciências (LINSINGEN, 2008) e Literatura não-canônica de divulgação científica em aulas de ciências (PINTO, 2009).

O trabalho de Piassi (2007) descreve o desenvolvimento de instrumentos teóricos de análise para lidar com a ficção científica a partir do ponto de vista do professor de ciências. Essas indicações foram resultantes da sua experiência com o uso de filmes, romances e contos da ficção científica para lecionar fisica, astronomia e outros tópicos de ciência em sala de aula, tanto para discutir os conceitos, as leis e os fenômenos da ciência como também os mecanismos de produção do conhecimento científico e a relação entre o trabalho da ciência e o contexto social. Tais instrumentos foram desenvolvidos sob a constatação de que a ficção científica nas aulas de ciências é comumente abordada sob duas formas tidas como ingênuas: “[...] a identificação dos erros (ou acertos) conceituais de ciência nas obras de ficção científica ou a discussão dos diversos níveis de distorção em 
relação a ciência e aos cientistas 'reais' nelas apresentadas" (PIASSI, 2007, p. 11).

Segundo o autor, a ficção científica assume uma construção empreendida sobre um discurso social da ciência e, por isso, ao invés de erros e distorções, existem certas posições ideológicas sobre a ciência que podem ser descritas como polos temáticos e que representam crenças ou descrenças dos papéis da ciência na sociedade. Para descrever os elementos de uma história de ficção científica, o autor criou como critério de análise os elementos contra factuais, em substituição à dicotomia erro/acerto, não para valorizar alguma precisão científica, mas para servir como construtos ficcionais para gerar específicos efeitos literários no leitor (PIASSI, 2007). Nesta abordagem, a precisão científica acha-se submetida à lógica do discurso literário e à intencionalidade do autor.

Algumas atividades desenvolvidas em sala de aula descritas no estudo ocorreram antes do início da pesquisa, por isso, elas não serviram para uma validação empírica da teoria nem para um processo sistemático de coleta de dados, pois, o objetivo delas neste trabalho foi ilustrar e desenvolver alguns detalhes da análise teórica e de como esta pode ser realizada para levar a atividades concretas de sala de aula (PIASSI, 2007). Também foram discutidos alguns aspectos específicos de adaptação ao contexto de sala de aula dos três gêneros de ficção científica, quais sejam, filmes, romances e contos.

Em outro trabalho, Piassi (2013) apresenta propostas do uso da ficção científica no ensino de ciências com base em estudos literários críticos sobre o gênero. Conforme argumentado no trabalho, a maior contribuição da ficção científica para a educação científica não se encontra em aspectos importantes como precisão científica, qualidade 
didática e potencial lúdico, mas na relevância que os mecanismos de produção ficcional têm para as aulas de ciências que envolvem um modo especial de se raciocinar e refletir sobre o mundo natural. Estes mecanismos estão fundamentados em conjecturas que proporcionam o estranhamento cognitivo que motiva a problematização nos alunos, a qual se pode assumir como ponto de partida para uma abordagem crítica de leis e conceitos e de suas motivações e implicações epistemológicas e socioculturais.

Groto e Martins (2015b), em outro artigo, exploram certos aspectos acerca das visões e da natureza da ciência em aulas de ciências com o uso de três obras da literatura de Monteiro Lobato: Reinações de Narizinho, A reforma da natureza e A chave do tamanho. Após análise dos livros, os autores verificaram que em todos existem trechos relacionados com o conhecimento científico, o que resultou na classificação desses trechos em quatro categorias: linguagem científica, visão de cientista, método científico e valoração da ciência. De acordo com a conclusão das pesquisadoras, estas obras podem ser empregadas no Ensino Fundamental, em especial para problematizar as visões de ciência e de cientista, muito embora se configurem como histórias compostas de elementos de visões de ciência inadequadas conforme apontadas em alguns estudos da área da Didática das Ciências.

Silochi (2008) realizou uma investigação para averiguar de que forma pesquisadores têm feito aproximações entre Literatura e o Ensino de Ciências, por meio de textos literários no processo de ensino e aprendizagem de Ciências e de Química. Essa investigação compreendeu a metodologia da pesquisa qualitativa-bibliográfica com base em dezesseis artigos publicados durante os anos 2000 a 2012 em 
revistas das áreas de Educação e Ensino, e nos eventos Encontro Nacional de Pesquisa em Educação em Ciências (ENPEC) e o Encontro Nacional de Ensino de Química (ENEQ) e que estavam relacionados com o assunto Literatura-Ensino de Ciências. A análise envolveu a categorização destes artigos em consonância com o referencial teórico da Análise Textual Discursiva, cujo objetivo foi de levantar a motivação a partir de textos literários no Ensino de Ciências. Os resultados, de modo geral, apontaram que os autores utilizam os textos literários para promover a aprendizagem dos conteúdos científicos tanto no ensino Fundamental e Médio, como também no Superior.

Em seu artigo, Carvalho (2007) enquadra a biologia como produção cultural e põe em discussão os significados que estão presentes em trechos da literatura de Monteiro Lobato, em especial, no livro "A Chave do Tamanho". Com base nos estudos de Derrida, este estudo põe em xeque alguns traços biológicos como tamanho, evolução e mundo biológico que sofrem hibridizações e se misturam a outros sentidos e definições e que acabam por se envolver e se infiltrar nas teias de relações e significações que ocorrem entre as diferentes esferas dos variados conhecimentos. O autor concluiu que as diferentes relações existentes entre a Literatura e a Biologia passam por um processo de hibridização e que algumas narrativas que são levadas para a Literatura, estão carregadas de valores, crenças, interesses e intenções políticas, aspectos também presentes no discurso científico, e, portanto, merecem ser exploradas pelos professores em sala de aula.

As obras de ficção científica voltam a ser o assunto de Piassi e Pietrocola (2009), onde afirmam que elas são um recurso importante para o ensino de ciências. Conforme os autores, a ficção científica, por meio do cinema e da literatura, além de ser um recurso didático, pode 
facilitar o aprendizado de ciências, e também se apresenta como uma modalidade de discurso sobre a ciência o qual expressa interesses e preocupações acerca de questões científicas que influenciam no âmbito sociocultural.

Os autores propõem uma metodologia de análise do conteúdo de obras de ficção científica em sua relação com o conhecimento científico, buscando evidenciar, por meio de elementos de análise literária e de semiótica, o processo de construção dos elementos denominados como contra factuais. Por meio dessa análise, concluem os autores que a obra se caracteriza não apenas como um simples recurso didático, mas como um discurso conduzido por mecanismos ficcionais, os quais possibilitam veicular ideias, posições e debates acerca de temas científicos. O desfecho da pesquisa resultou na criação de uma categorização desses elementos baseada na semiótica greimasiana e com o emprego de lexemas, sendo que cada uma dessas categorias se destina a representar distintos mecanismos narrativos e com o potencial de serem exploradas de diferentes maneiras em termos didáticos.

A literatura infantil foi o objeto de estudo do artigo de Linsingen (2008), que a caracteriza como lúdica, atrativa e dinâmica, tornando-a indispensável no cotidiano escolar. Segundo a autora, a literatura estimula a leitura e ajuda na formação de consciência de mundo e, por ser fonte de conhecimento, não pode ter um conteúdo equivocado, falso ou mistificado. A pesquisa foi fazer uma análise do conteúdo de Ciências que está presente em sete livros de Literatura Infantil disponíveis no acervo de seis escolas públicas de Chapecó (SC), destinados a alunos dos anos iniciais do ensino fundamental. Os resultados apontaram a existência de tipologias variadas de conteúdos, 
com destaque para os conteúdos conceituais e atitudinais; também identificaram algumas inconsistências em certos conteúdos, principalmente acerca da morfologia de alguns animais, algumas questões referentes à reprodução e ciclo de vida, às relações entre os animais e do seu habitat. Por fim, a pesquisa concluiu que, apesar de muito vantajoso, a associação da Literatura Infantil no ensino de Ciências precisa de um pouco de cautela para não se tornar um obstáculo, devido à existência de erros e inconsistências em alguns conteúdos que podem resultar num ensino equivocado de Ciências.

A abordagem trazida por Pinto (2009) faz inicialmente diferenciações entre a divulgação científica canônica e a não canônica. O objetivo do estudo foi analisar algumas narrativas de obras não canônicas de literatura, visando destacar suas potencialidades ao ensino de ciências. De acordo com o autor, o estudo possibilitou detectar alguns elementos nessas obras que são de fundamental importância para a reflexão sobre a vida humana e sobre a ciência, entre eles, a narrativa resultante da imaginação criadora pela via da capacidade humana e por sua potencialidade criativa. Concluiu com destaque para a obra "Meninos da planície", de Cástor Cartelle (2001), a qual traz contribuições para a renovação do ensino de ciências, pois o teor central da obra é uma reflexão a respeito da humanização dos sujeitos, embora contenha, sem prejuízos, traços de transmissão de conteúdos da ciência numa dimensão de formação científica.

\section{RESULTADOS E DISCUSSÃO}

Os resultados desta revisão dos 13 trabalhos selecionados nos permitiram chegar a algumas considerações acerca da pesquisa sobre a relação literatura e ensino de ciências, sejam dos trabalhos empíricos ou dos teóricos e que são apresentadas a seguir. 
Uma primeira observação foi a existência de mais pesquisas teóricas, sem a intervenção do pesquisador em campo, visto que, em mais da metade dos trabalhos, ou seja, 8 de 13, os autores realizaram análise literária, revisão bibliográfica ou proporam algum instrumento de análise.

Uma destas caraterísticas que ficou muito evidente, é o interesse dos pesquisadores pelas obras de Monteiro Lobato. Os estudos de Groto e Martins (2015b) e Carvalho (2007) envolveram pesquisas em que foram feitas análises literárias da obra e os estudos de Groto (2012) e Groto e Martins (2015a) foram experenciadas por meio de intervenções em sala de aula. De um modo geral, estes trabalhos por serem praticamente de um mesmo grupo de pesquisa, concordam e aprofundam sobre a possibilidade de inclusão das obras de Monteiro Lobato no ensino de ciências. Consideram os autores que a discussão advinda dessas obras, oportunizam a interação e a dialogicidade dos alunos na sala de aula e, como suporte didático, possuem um potencial para a contextualização e a problematização dos conteúdos científicos.

Outra característica marcante foi a repetição dos autores nos títulos pesquisados, como Piassi (2007) e Piassi (2013), e escrito em colaboração como em Piassi e Pietrocola (2009) e também Groto (2012), Groto e Martins (2015a) e Groto e Martins (2015b). Observa-se, assim, que alguns artigos são produto ou parte de uma pesquisa maior, tese ou dissertação de mestrado, levando à consideração de que esse tema (literatura e ensino de ciências) é explorado recorrentemente pelos mesmos grupos de pesquisadores.

Alguns trabalhos (GROTO, 2012; GROTO; MARTINS, 2015a; GROTO; MARTINS, 2015b; LINSINGEN, 2008) revelaram que algumas 
obras de literatura trazem erros conceituais, informações e desenhos equivocados que não retratam de forma correta os conteúdos científicos e, por isso, recomendam atenção por parte dos professores para que não disseminem conhecimentos e conceitos errados. A ficção científica foi assunto dos trabalhos de Piassi (2007), Piassi (2013) e Piassi e Pietrocola (2009) e constataram que a aproximação deste gênero literário no ensino possibilita discutir os conceitos, as leis e os fenômenos da ciência, os mecanismos de produção do conhecimento científico e a relação entre o trabalho da ciência e o contexto social.

Pudemos verificar que não houve semelhanças entre os trabalhos, pois, alguns se mostraram bem específicos em suas abordagens, como o trabalho de Carvalho (2007) que tratou do ensino de Biologia, Silochi (2008) sobre o ensino de Química e Pinto (2012) acerca de obras canônicas e não-canônicas. O ponto em comum entre eles é que os autores concordam que a relação da literatura no ensino de ciências se mostra muito positiva para promover o diálogo produtivo no processo de ensino-aprendizagem.

\section{CONSIDERAÇÕES FINAIS}

O objetivo dessa revisão foi investigar o que tem sido produzido acerca da relação ensino de ciências e literatura e de que forma essa relação tem sido trabalhada no ensino fundamental dentro do espaço escolar.

Das análises dos autores sobre as aproximações da literatura no ensino de ciências, observamos que as questões apontadas por eles se restringem à dimensão estrita do "Ensino de" com a literatura. Importante assinalar que mesmo com referenciais teóricos distintos, não discutiram sobre a prática da leitura em si, enquanto possibilidade para atuar numa formação que busca ampliar a 
criatividade, a abstração e a reflexão. Interessante essa característica, pois, para além dos conteúdos científicos, a prática de leitura carrega uma potencialidade que parece não ser valorizada pelos autores, ainda que a reconheçam. Tampouco houve trabalhos que discutiram o espaço da biblioteca, enquanto local para promover atividades relacionadas à literatura e ensino de ciências. Isso pode nos indicar que, tendencialmente, o ensino de ciências é visto como uma atividade própria para a sala de aula, os laboratórios e os museus, em detrimento da biblioteca, espaço próprio para as obras literárias.

O hábito da leitura, tanto na sala de aula quanto nas bibliotecas das escolas, cumpre um papel fundamental para a formação do leitor que, por conseguinte, acabam por influenciar também na formação escolar de qualidade. A biblioteca neste contexto se insere como um local que ainda preserva a função de dar acesso às informações, espaço em que pode mediar a produção do conhecimento. A oportunidade de ler tem como horizonte a autonomia dos alunos, o contato com outras realidades e conhecimentos e, também, com a linguagem científica.

A maioria dos trabalhos analisados apresentou propostas de aproximação com as obras ou trechos delas para o ensinoaprendizagem de ciências. Segundo esses autores, a inclusão de textos literários em sala de aula pode ser ponto de partida para a problematização e a investigação, atividades importantes para o processo de formação crítica em relação aos conhecimentos científicos. Também indicaram a possibilidade de realizar de forma interdisciplinar, pois, acreditam que a literatura auxilia e ajuda o docente em sala de aula para a compreensão e apreensão dos conteúdos científicos. 
Cabe novamente ressaltar, que há limitações nesses estudos no que diz respeito ao alcance do trabalho com a literatura: trata-se de melhorar a aprendizagem de conteúdos científicos, mas não para questionar a ciência e a tecnologia. Nesse sentido, acabam por assumir uma perspectiva de trabalho mais conteúdista do que de uma formação crítica da realidade social. Não há possibilidade de pensar numa formação crítica, sem questionar e debater sobre a ciência em si e suas aplicações materializadas nas tecnologias.

Embora não seja um tema inédito para a pesquisa, os resultados expostos no presente artigo acerca da relação literatura e ensino de ciências não esgotam todas as perspectivas de análise acerca do tema. É uma temática que merece ser mais explorada, não só nas pesquisas de revisão da literatura, mas também de experiências práticas. Esse estudo nos possibilitou conhecer algumas tendências e algumas carências de pesquisas. No que tange à relação biblioteca e ensino de ciências, pudemos observar que se trata de um assunto muito pouco explorado, quase inédito, pois, não foi recuperado na busca nenhum artigo que tratasse dessa relação. Isso nos indica um campo de pesquisa que poderá contribuir para o ensino de ciências ou a educação de modo geral, pois nos parece urgente retomar outros espaços escolares que possam ser voltados para uma formação realmente crítica e democrática para os estudantes.

\section{REFERÊNCIAS}

BRASIL. Diretrizes Curriculares Nacionais Gerais da Educação Básica. Ministério da Educação. Secretaria de Educação Básica; Diretoria de Currículos e Educação Integral. Brasília: MEC, SEB, DICEI, 2013a. . Educação brasileira: indicadores e desafios: documentos de consulta. Fórum Nacional de Educação. Brasília: MEC, SE, SEA, 2013b. Disponível em: 
<http:/ /conae2014.mec.gov.br/images/pdf/educacao_brasileira_indicadores _e_desafios.pdf>. Acesso em: 29 nov. 2016.

CABRAL, I. de O. N. O sapo virou príncipe: construção do conhecimento sobre a Classe Amphibia a partir de contos infantis e sua importância no Ensino de Ciências. 2014. 161f. Dissertação (Mestrado em Ensino em Biociências e Saúde) - Fundação Oswaldo Cruz, Instituto Oswaldo Cruz, Rio de janeiro, 2014.

CARTELLE, Castor. Os meninos da planície: histórias de um Brasil antigo. Belo Horizonte: Formato, 2001.

CARVALHO, F. A. Biologia e cultura: significações partilhadas na literatura de Monteiro Lobato. Ensaio Pesquisa em Educação em Ciências, Belo Horizonte, v. 9, n. 2, p. 238-253, jul./dez. 2007.

GIRALDELLI, C. G. C. M.; ALMEIDA, M. J. P. M. de. Leitura coletiva de um texto de literatura infantil no ensino fundamental: algumas mediações pensando o ensino das ciências. Ensaio Pesquisa em Educação em Ciências, Belo Horizonte, v. 10, n. 1, p.44-62, jan./jun. 2008.

GREIMAS, A. J. Semântica estrutural. 2. ed. São Paulo: Cultrix; Edusp, 1976.

GROTO, S. R. Literatura de Monteiro Lobato no Ensino de Ciências. 2012, 184 f. Dissertação (Mestrado em Educação) - Programa de Pós-Graduação em Educação, Centro de Educação, Universidade Federal do Rio Grande do Norte, Natal, 2012.

GROTO, S. R.; MARTINS, A. F. P. A literatura de Monteiro Lobato na discussão de questões acerca da natureza da ciência no ensino fundamental. Ensaio Pesquisa Educação em Ciências, Belo Horizonte, v. 17, n. 2, p. 390413, mai./ago. 2015.

Monteiro Lobato em aulas de ciências: aproximando ciência e literatura na educação científica. Ciência e Educação, Bauru, v. 21, n. 1, p. 219-238, 2015.

LINSINGEN, L. Literatura infantil no ensino de ciências: articulações a partir da análise de uma coleção de livros. Dissertação (Mestrado em Educação Científica e Tecnológica) - Programa de Pós-Graduação em Educação Científica e Tecnológica, Centro de Ciências da Educação, Universidade Federal de Santa Catarina, Florianópolis, 2008.

MAINGUENEAU, D. Discurso literário. São Paulo: Contexto, 2006. MARCUSE, Herbert. Ideologia da Sociedade Industrial. 3. ed. Tradução; Giosone Rebuá. Rio de Janeiro: Zahar, 1969.

NEVES, T. M. A brincadeira, o jogo, o lúdico e a literatura infantil nas salas de alfabetização. 2013. 50 f. Trabalho de Conclusão de Curso (Licenciatura em Pedagogia) -Faculdade de Educação, Universidade de Brasília, Brasília, 2013.

PALCHA, L. S.; OLIVEIRA, O. B. de. A evolução do ovo: quando leitura e literatura se encontram no ensino de ciências. Ensaio Pesquisa Educação em Ciências, Belo Horizonte, v. 16, n. 1, p. 101-114, jan./abr. 2014. 
PIASSI, L. P. C. A ficção científica e o estranhamento cognitivo no ensino de ciências: estudos criticos e propostas de sala de aula. Ciência \& Educação, v. 19, n. 1, p. 151-168, 2013.

. Contatos: a ficção científica no ensino de ciências em um contexto sócio cultural. 2007. 462 f. Tese (Doutorado em Educação) - Faculdade de Educação, Universidade de São Paulo, 2007.

PIASSI, L. P. C.; PIETROCOLA, M. Ficção científica e ensino de ciências: para além do método de 'encontrar erros em filmes'. Educação e Pesquisa, São Paulo, v. 35, n. 3, p. 525-540, set./dez. 2009.

PINTO, G. Literatura não-canônica de divulgação científica em aulas de ciências. Ensaio Pesquisa Educação em Ciências, Belo Horizonte, v. 11, n. 2, p. 1-19, dez. 2009.

SANTOS, F. R. Detetive ou cientista? A literatura policial infanto-juvenil como recurso didático na educação em ciências. 2013. 112 f. Dissertação

(Mestrado em Ensino de Ciências) - Programa de Pós-Graduação Interunidades em Ensino de Ciências, Universidade de São Paulo, 2013. SANTOS, W. L. P. Educação científica humanística em uma perspectiva Freireana: resgatando a função do ensino de CTSA. Alexandria: Revista de Educação em Ciência e Tecnologia, v. 1, n. 1, p. 109-131, mar. 2008. Educação científica na perspectiva de letramento como práticas sociais: funções, princípios e desafios. Revista Brasileira Educação [online], v. 12 , n. 36 , p 474-492, 2007b.

SANTOS, W. L. P.; MORTIMER, F. M. Uma análise de pressupostos teóricos da abordagem C-T-S (Ciência - Tecnologia - Sociedade) no contexto da educação brasileira. Ensaio Pesquisa em Educação em Ciências, v. 2, n. 2, p.1-23, dez. 2002.

SILOCHI, J. Aproximações entre literatura e ciência: um estudo sobre os motivos para utilizar textos literários no ensino de ciências. 2014, $260 \mathrm{f}$. Dissertação (Mestrado em Educação em Ciências e em Matemática) Programa de Pós-Graduação em Educação em Ciências e em Matemática, Universidade Federal do Paraná, Curitiba, 2014. 